\title{
DE NOVO INTERSTITIAL DELETION OF 4q[46,XX,del(4)(q27q28.2)] WITH INTACT BLOOD GROUP-MN LOCUS, CONFINING ITS LOCUS TO 4q28.2-4q31.1
}

\author{
Keiko WaKuI, ${ }^{1}$ Toshiro Nishida, ${ }^{1}$ Jun-ichiro Masuda, ${ }^{1}$ Takeshi ItoH, ${ }^{1}$ \\ Daisuke Katsumata, ${ }^{2}$ Tsutomu Ohno, ${ }^{2}$ and Yoshimitsu Fukusirma ${ }^{3}$ \\ ${ }^{1}$ Department of Clinical Laboratory, Divisions of ${ }^{2}$ Neonatology and ${ }^{3}$ Medical Genetics, \\ Saitama Children's Medical Center, Magome, Iwatsuki, Saitama 339, Japan
}

\begin{abstract}
Summary We report a malformed female infant with de novo interstitial deletion of 4q[46,XX, del(4)(q27q28.2)]. The MN blood type analysis of the family members showed that the patient had an intact blood group$\mathrm{MN}$ locus. The locus of the gene responsible for the $\mathrm{MN}$ antigen activity is confined to a $4 q 28.2-4 q 31.1$ segment on the basis of the result of this patient and the previous mapping data.
\end{abstract}

Key Words interstitial deletion of 4q, blood group-MN locus, glycophorin A, gene mapping

\section{INTRODUCTION}

An interstitial deletion of the middle portion of $4 \mathrm{q}$ is rare. There have been, to our knowledge, only 3 reported cases of an interstitial deletion involving the 4q28 band (Serville and Broustet, 1977; Mitchell et al., 1981; Torrado et al., 1982). The blood group-MN locus has been assigned to 4q28-4q31.1 (Divelbiss et al., 1989). We describe here a malformed infant with an interstitial deletion of $4 \mathrm{q} 27-$ $4 \mathrm{q} 28.2$ and the intact blood group-MN locus.

\section{CASE REPORT}

The patient is the third child of a 41-year-old father and a 35-year-old mother, who are both healthy and nonconsanguinous. A 3-year-old elder brother is healthy and not malformed, but the second child was delivered as a stillbirth at the 36th week of pregnancy. The patient was born at 35 th week of gestation by cesarean section because of breech presentation. Her birth weight was $2,580 \mathrm{~g}$, length 43 $\mathrm{cm}$ and head circumference (OFC) $33 \mathrm{~cm}$. She was complicated with neonatal asphyxia and referred to the neonatal intensive care unit of our medical center.

Received December 9, 1990; Accepted December 22, 1990. 
The following anomalies were noticed: a narrow and hirsutulous forehead, hypertelorism, downward slanting of palpebral fissures, a suddle nose, a high-arched narrow palate, retrognathia with a pointed chin, large ears, a wide neck with redundant skin, wide-set nipples and hypoplastic nails (Fig. 1). Ventricular septal defect was noticed at birth by echocardiography, but it was spontaneously closed by age 9 month. Her developmental milestones were moderately retarded: head control at 5 months, sitting unsupported at 8 months and crawling at 11 months.
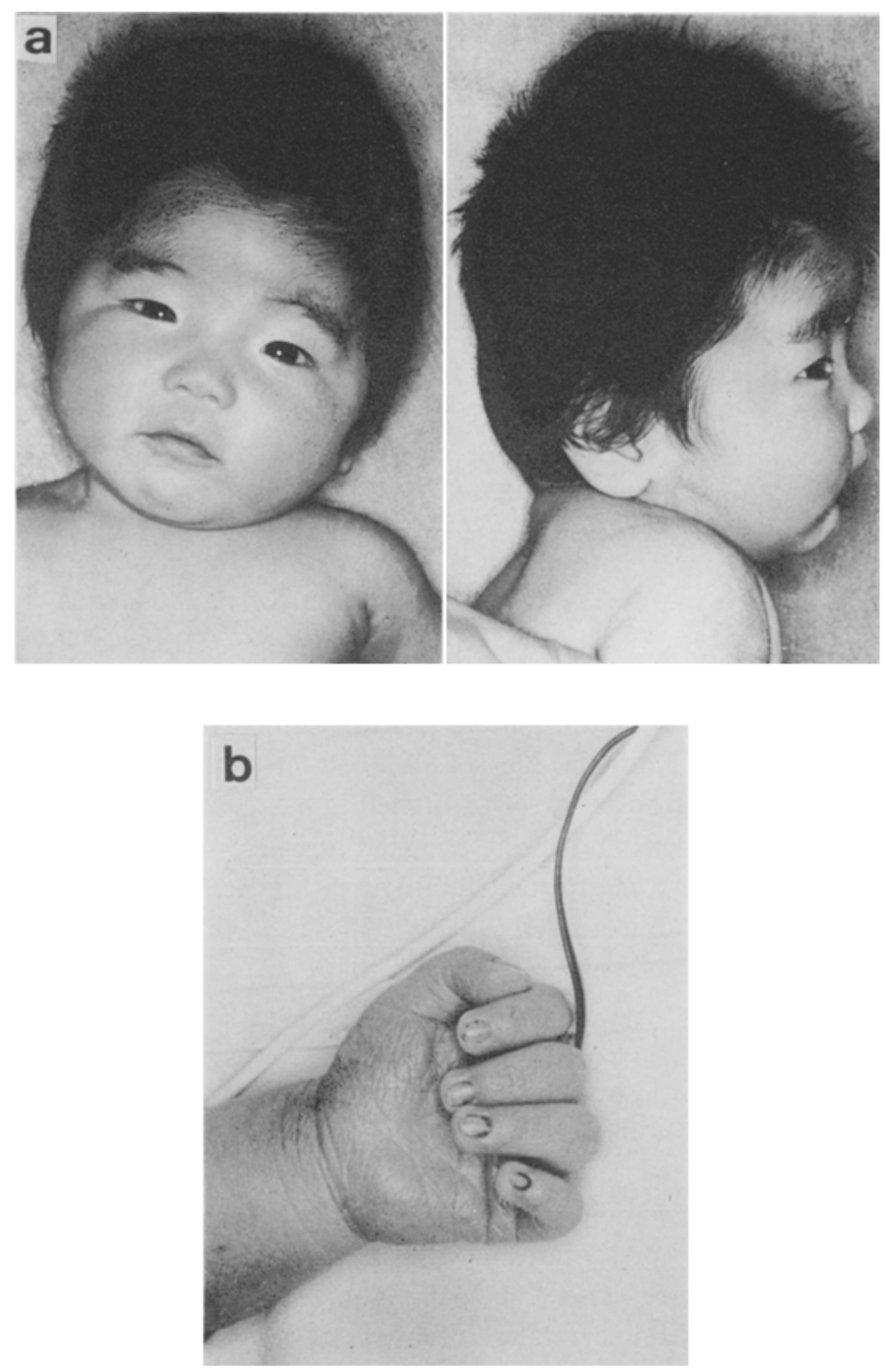

Fig. 1. (a) The patient at age 11 months. (b) Hypoplastic nails of the left fingers. 

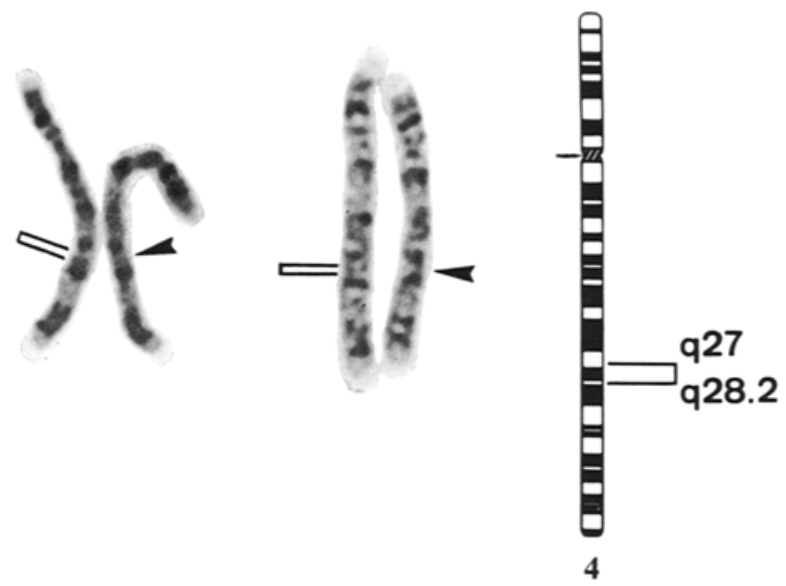

Fig. 2. High-resolution G-banded chromosomes 4 of the patient. Chromosome 4 on the right shows a deletion of bands $4 \mathrm{q} 27$ through 28.2 .

Chromosome preparations were obtained from 3-day cultures of peripheral blood lymphocytes. Standard trypsin G-banding study showed imbalance of 4q. Prometaphase plates at the 850-band stage were collected, and chromosomes were GTG-banded. Special attention was focused on the chromosome 4 pairs. The patient had an interstitial deletion of $4 \mathrm{q}$ involving a segment from a distal part of band q27 to a proximal part of q28.2 (Fig. 2). The parents' chromosomes were normal. Thus, the karyotype of the patient was interpreted as $46, \mathrm{XX}$, del(4)(q27q28.2) de novo.

MN blood types of the patient and her parents were analyzed by the saline method. The genotype of the patient was $\mathrm{MN}$, the father $\mathrm{MN}$ and the mother $\mathrm{MM}$, indicating the intact blood group-MN locus in the patient.

\section{DISCUSSION}

An interstitial deletion of the middle portion of $4 \mathrm{q}$ involving the $4 \mathrm{q} 28$ band has been reported only in 3 cases (Servilleand Broustet, 1977; Torrado et al., 1982; Mitchell et al., 1981). Deleted segments of these 3 cases varied: 4q24-4q32 in Serville and Broustet (1977), 4q27-4q31 in Torrado et al. (1982) and 4q27-4q31.22 in Mitchell et al. (1981). The present case has an interstitial deletion of $4 \mathrm{q} 27$ $4 \mathrm{q} 28.2$, which is the smallest deletion of the long arm of chromosome 4 . A case of Serville and Broustet (1977) had a larger deletion and the clinical findings quite differ from those of our case. Comparison of the clinical manifestations in the other 2 cases of $4 q$ - with those in our case is shown in Table 1. Common manifestations among the 3 patients are not observed except for micrognathia, hypoplastic nails and mental retardation. These different phenotypes are likely due to differencies of their deleted regions. 
Table 1. Comparison of clinical data of patients with interstitial deletion at the middle portion of $4 \mathrm{q}$.

\begin{tabular}{|c|c|c|c|}
\hline & $\begin{array}{l}\text { Mitchell et al. } \\
\quad(1981)\end{array}$ & $\begin{array}{c}\text { Torrado et al. } \\
(1982)\end{array}$ & Present case \\
\hline Deleted segments & $\mathrm{q} 27-\mathrm{q} 31.22$ & $\mathrm{q} 27-\mathrm{q} 31$ & $\mathrm{q} 27-\mathrm{q} 28.2$ \\
\hline Age (years) & $26 / 12$ & 11 & $11 / 12$ \\
\hline Sex & Female & Male & Female \\
\hline Maternal/paternal age (years) & $31 / 32$ & $21 / 27$ & $35 / 41$ \\
\hline Birth weight $(\mathrm{g}) /$ Gestational age (weeks) & $2,260 / 38$ & $3,100 / 40$ & $2,580 / 35$ \\
\hline Mental retardation (IQ) & severe & moderate $(60)$ & moderate \\
\hline Growth failure & + & + & - \\
\hline Hypotonia & + & & - \\
\hline Brachycephaly & & $t$ & - \\
\hline Large anterior fontanel & + & & - \\
\hline Narrow and hirsutulous forehead & & & + \\
\hline Flat occiput & + & & - \\
\hline Prominent mid-face & + & & - \\
\hline Facial asymmetry & & + & - \\
\hline Prominent supraorbital ridges & + & + & - \\
\hline Shallow orbital ridges & & + & - \\
\hline Down-slanted palpebral fissures & + & & + \\
\hline Epicanthus & + & & - \\
\hline Hypertelorism & + & & + \\
\hline Ptosis of eyelis & + & & - \\
\hline Deviated nose & & + & - \\
\hline Suddle nose & & & + \\
\hline Depressed nasal bridge & + & & - \\
\hline Long philtrum & & + & - \\
\hline Small mouth & & + & - \\
\hline Micro-/retrognathia & + & + & + \\
\hline Irregular placement of teeth & & + & - \\
\hline High-arched palate & & + & + \\
\hline Wide neck with redundant skin & & & + \\
\hline Low posterior hair-line & & + & - \\
\hline Ears & small & small & large \\
\hline Low-set ears & + & + & - \\
\hline Hypoplastic helices & + & & - \\
\hline Posteriorly rotated ears & & + & - \\
\hline Widely spaced nipples & & + & + \\
\hline Hypoplastic nails & + & + & + \\
\hline 5th-finger clinodactyly & + & & - \\
\hline Simian creases & + & + & - \\
\hline Pes valgus & + & & - \\
\hline Small testes & & + & \\
\hline Ventricular septal defect & + & - & + \\
\hline
\end{tabular}


$\mathrm{MN}$ blood type antigen activity is derived from the major sialoglycoprotein on the erythrocyte membrane, i.e., glycophorin A (GYPA). The GYPA gene has been mapped by various techniques to $4 \mathrm{q} 28-4 \mathrm{q} 31$ (Mattei et al., 1987). Divelbiss et al. (1989) refined on the physical location of the gene to $4 \mathrm{q} 28-4 \mathrm{q} 31.1$, based on the results of in situ hybridization study on a malformed patient with an apparently balanced translocation between $2 \mathrm{q} 14.2$ and 4q31.1. The MN blood type analysis of the present family showed $\mathrm{MN}$ in the father, $\mathrm{MM}$ in the mother and $\mathrm{MN}$ in the patient. These findings indicate that the blood group-MN locus is intact in the patient. Since the patient has an interstitial deletion of $4 \mathrm{q} 27-4 \mathrm{q} 28.2$, the MN locus does not exist in this region. Thus, the blood group-MN locus is confined to $4 \mathrm{q} 28.2-4 \mathrm{q} 31.1$.

Acknowledgments We are grateful to Prof. Norio Niikawa (Department of Human Genetics, Nagasaki University School of Medicine) for his helpful advice.

\section{REFERENCES}

Divelbiss, J., Shiang, R., German, J., Moore, J., Murray, J.C. and Patil, S.R. 1989. Refinement of the physical location of glycophorin $\mathrm{A}$ and $\beta$ fibrinogen using in situ hybridization and RFLP analysis. Tenth International Workshop on Human Gene Mapping. Cytogenet. Cell Genet. 51: 991 (Abstract).

Mattei, M.G., London, J., Rahuel, C., d'Auriol, L., Colin, Y., Le Van Kim, C., Mattei, J.F., Galibert, F. and Cartron, J.P. 1987. Chromosome localization by in situ hybridization of the gene for human erythrocyte glycophorin to region 4q28-31. Ninth International Workshop on Human Gene Mapping. Cytogenet. Cell Genet. 46: 658 (Abstract).

Mitchell, J.A., Packman, S., Loughman, W.D., Fineman, R.M., Zackai, E., Patil, S.R., Emanuel, B., Bartley, J.A. and Hanson, J.W. 1981. Deletions of different segments of the long arm of chromosome 4. Am. J. Med. Genet. 8: 73-89.

Serville, F. and Broustet, A. 1977 . Pericentric inversion and partial monosomy 4q associated with congenital anomalies. Hum. Genet. 39: 239-242.

Torrado, M.D.V., Labarta, J.D. and Migliorini, A.M. 1982. Interstitial deletion of the long arm of chromosome 4 in a patient with mental retardation and abnormal phenotype. J. Med. Genet. 19: 477. 